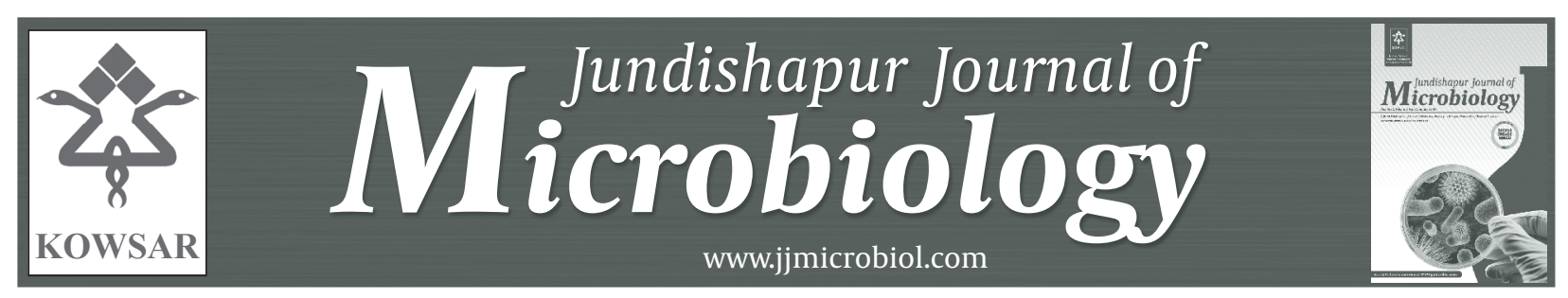

\title{
Bio-Deterioration of Library Materials: Study of Fungi Threatening Printed Materials of Libraries in Isfahan University of Medical Sciences in 2011
}

\author{
Mostafa Chadeganipour ${ }^{1}$, Rezvan Ojaghi ${ }^{2^{*}}$, Hossein Rafiei ${ }^{1}$, Mina Afshar ${ }^{2}$, Seiyede \\ Tayyebeh Hashemi ${ }^{1}$ \\ ${ }^{1}$ School of Medicine, Isfahan University of Medical Sciences, Isfahan, IR Iran \\ ${ }^{2}$ School of Management and Medical Information Science, Isfahan University of Medical Sciences, Isfahan, IR Iran \\ * Corresponding author: Rezvan Ojaghi, School of Management and MedicalInformation Science, Isfahan University of Medical Sciences, Hezarjerib av- \\ enue, Isfahan, IR Iran. Tel.: +918-9285498, Fax: E-mail: rezvan_ojaqhi@yahoo.com
}

\section{A B S T R A C T}

Background: The importance of preserving and maintaining printed materials is crucial for the libraries. Fungi play the main role in destroying wood and paper.

Objectives: This research aimed to study and identify threatening fungal agents of library resources in Isfahan University of Medical Sciences. Materials and Methods: This is a descriptive analytical study. 126 samples were collected and examined for the presence of fungi. An open plate method was used to scan airborne fungal contents and triplicate samples were collected at four different locations in the morning, at noon, and in the evening. The fungal culture media were incubated at $25-30{ }^{\circ} \mathrm{C}$ until growth appeared and then the fungi colonies were identified by routine mycological laboratory methods.

Results: 1265 colonies of fungi belonging to 26 genera were identified in the air and different surfaces of books (references and circulation departments) and also surfaces of shelves in libraries. Cladosporium sp., Penicillium sp., Aspergillus sp. and Alternaria sp. were the most common isolated fungi in libraries of Isfahan University of medical sciences.

Conclusions: We suggest training librarians as one of the most important steps in libraries to preserve library materials because having no knowledge about threatening factors and the way to fight with them are the main reasons of most frequent damages to library resources. Using new methods and technologies of preserving and maintenance of materials should be a priority in library managers' planning.

Keywords: Mold; Library Materials; Fungi

Copyright ( ) 2013, Kowsar Corp.; Published by Kowsar Corp.

-Article type: Research Article; Received: 06 Mar 2012, Revised: 07 May 2012, Accepted: 21 May 2012; DOI: 10.5812/jjm.4751

-Implication for health policy/practice/research/medical education:

The implication of study is for prevention of damage and preserving library collections, environmental conditions should be adjusted in a way that fungal growth diminishes along with the training librarians. Beside the role of these fungi in infecting immunocompromised hosts, information obtained in the present study contribute toward a better understanding of the pattern of occurrence of allergen airborne fungi, and may be valuable for librarians handeling these printed materials.

-Please cite this paper as:

Chadeganipour M, ojaghi R, Rafiei H, Afshar M, Hashemi ST. Bio-deterioration of Library Materials: Study of Fungi Threatening Printed Materials of Libraries in Isfahan University of Medical Sciences in 2011.Jundishapur J Microbiol. 2013;6(2):127-131. DOI:10.5812| jjm.4751

-Copyright ( 2013 Ahvaz Jundishapur University of Medical Sciences; Published by Kowsar Corp.

This is an Open Access article distributed under the terms of the Creative Commons Attribution License (http://creativecommons.org/licenses/by/3.0), which permits unrestricted use, distribution, and reproduction in any medium, provided the original work is properly cited. 


\section{Background}

Paper has been the most dominant tool for recording human knowledge and its spoilage is one of the most serious dangers for libraries and archives. Studies have shown that majority of people use printed materials despite of existence and currency of electronic copies (1). So the importance of preserving and maintaining printed materials is crucial for librarians and specialists in libraries and information centers. Fungi are decomposing organisms that play the main role in destroying and degrading carbon and residue of nitrogen such as wood and paper (2). The ability of fungi to produce extracellular enzymes is well established. They can produce hydrolytic enzymes such as cellulase, xylanase, pectinase, etc. To date most of the studies have been limited to species of Aspergillus, Fusarium, Trichoderma, Myrothecium, and Penicillium (3).

Basidiomycetes are lignin decomposers (4) and Trichosporon cutaneum, T. pullulans, and Cryptococcus spp. are pectate decomposers (5). Also some strains of T. cutaneum and T.pullulans possess considerable xylanase (6). There is a weak air flowing in libraries' stock where more papers exist. Also, dust can be a good potential source for these fungi to feed and grow; these conditions intensify fungal contaminations (1). Bio-deterioration of library materials is a worldwide problem that causes great damage to especially unique manuscripts and books stored in the libraries (7). There are few studies about fungal contaminations in libraries.

Shamsian et al. (7) studied the fungal contaminations in Historical Manuscripts at Astan Quds Museum Library, Mashhad, Iran. They showed that the most fungal Genera were Aspergillus, Penicillium, and Mucor spp. Aspergillus and Penicillium spp. could damage paper. Zotti et al. (8) studied fungal bio-deterioration of historic paper and artistic works and revealed some fungal genera which colonized and damaged them. The colonies they isolated in frequency order were Penicillium, A. flavus, Cladosporium, and Auerobasidium spp. Vittal and Glory (9) found that Aspergillus sp. and Cladosporium sp. were the most common fungi among printed materials at library building of Madras University in India. Also existence of considerable amounts of Nigrospora, Curvularia, Drechslera, and Alternaria spp. was reported.

Guiamet et al. (10) found in their studies that Microbial concentrations on both repositories of the National Archive of the Republic of Cuba (NARC) and the Historical Archive of the Museum of La Plata (HAMP) consisted of Penicillium, Aspergillus, Cladosporium, Curvularia, Alternaria, Fusarium, and Syncephalastrum spp. Library environments, particularly the old ones, provide nutritional requirements of microorganisms in the form of old papers and paper glues. So, based on the geographical situation and weather condition, libraries contain more fungi both qualitatively and quantitatively compared to other closed places. Since the paper is made of cellulose and other materials, it can be destroyed and deteriorated by fungi. Therefore, protecting library materials that most of them such as manuscripts, books, magazines, paintings, tables, and maps are made of paper is necessary.

\section{Objectives}

This article aimed to study and identify threatening fungal agents of library resources in Isfahan University of Medical Sciences during 2011.

\section{Materials and Methods}

This is a descriptive analytical study. Based on statistical calculation, 126 samples were collected. In this survey, samples of the air, different surfaces of books (references and circulation departments), and also surfaces of shelves in libraries were examined for the presence of fungi. Libraries of all faculties in Isfahan University of Medical Sciences (management and medical information, medicine, rehabilitation, pharmacy and pharmaceutical sciences, health, dentistry, nursing and midwifery) were considered during the spring 2011. Sampling was scheduled to perform three times daily for each libraryin the morning after cleansing, at noon during the work session, and in the evening before closing daily work session.

In this study, the open plate method (11) was used for assessment of fungal spores in the air of libraries; the plates containing Sabouraud dextrose agar and chloramphenicol (SC, Merck, Germany) were put in altitude of 1.5 meter from the floor in the middle point of library exposing to the air for 15 minutes. Also sampling from surfaces of shelves and books were performed using moist sterile swabs afterwhich the swabs were cultured on SC medium at sterile conditions. Then, the plates were closed, labeled, and transferred to laboratory.
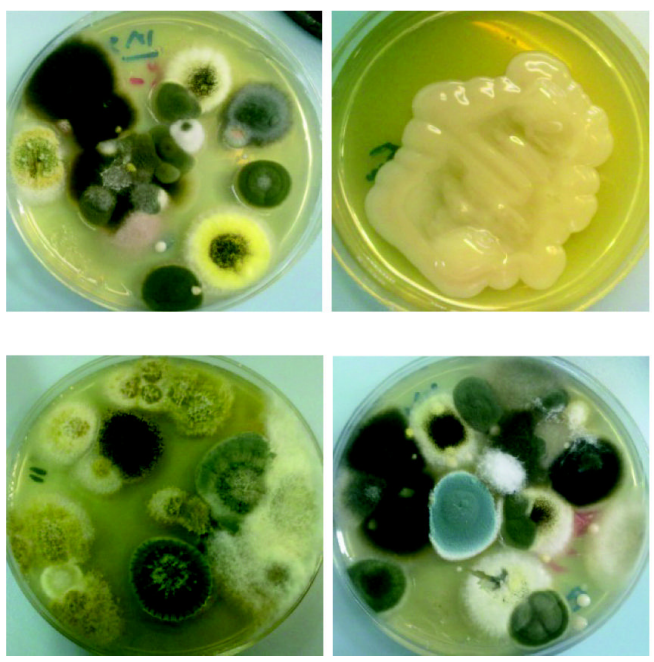

Figure 1. Some of the Isolated Fungal Colonies in Libraries 
All plates were put in an incubator at $25-30^{\circ} \mathrm{C}$ and examined for fungal growth for 20 days. Mould fungi grew on culture media were identified by macroscopic and microscopic standard procedures (12).Yeast colonies were tested by Germ tube and Chlamydoconidia production (13), and reported as Candida albicans and Candida sp. Finally after determining species and number of fungi colonies data were entered and studied through SPSS (SPSS Inc., Chicago IL) and analyzed statistically.

\section{Results}

After analyzing quantitative data of present study, 1265 colonies of fungi belonging to 26 genera were identified in the air, and different surfaces of books (references and circulation departments) and shelves in libraries (Table1). Library of faculty of management and medical information (library number 1) showed 47 colonies, of faculty of medicine (library number 2) 286 colonies, of faculty of rehabilitation (library number 3) 69 colonies, of faculty of pharmacy and pharmaceutical sciences (library number 4) 131 colonies, of faculty of health (library number5) 329 colonies, of faculty of dentistry (library number6) 297 colonies, and of faculty of nursing and midwifery (library number 7) 106 colonies (Figure 1).

Table 1. Number of Colonies of Different Fungi Isolated From Isfahan University of Medical Science, Iran, in Seven Different Libraries.

\begin{tabular}{ll}
\hline Source of Sampling & Frequency, No.(\%) \\
\hline Air & $52(4.1)$ \\
\hline Book borrow & $333(26.3)$ \\
\hline Book reference & $388(30.7)$ \\
Shelf & $492(38.9)$ \\
Total & $1265(100)$ \\
\hline
\end{tabular}

Table2.. Distribution of Isolated Fungal Colonies Based on the Source of Sampling

\begin{tabular}{|c|c|c|c|c|c|c|c|}
\hline \multicolumn{8}{|c|}{ Libraries } \\
\hline & L1 & L2 & L3 & L4 & L5 & L6 & L7 \\
\hline Acremonium & $0(0)$ & $2(0.7)$ & $0(0)$ & $1(0.8)$ & $0(0)$ & $1(0.3)$ & $1(0.9)$ \\
\hline Alternaria & $3(6.4)$ & $16(5.6)$ & $5(7.2)$ & $3(2.3)$ & $24(7.3)$ & $13(4.4)$ & $3(2.8)$ \\
\hline Aspergillus niger & $2(4.3)$ & $6(2.1)$ & $1(1.4)$ & $7(5.3)$ & $15(4.6)$ & $52(17.5)$ & $11(10.4)$ \\
\hline Aspergillus sp. & $4(8.5)$ & $3(1)$ & $0(0)$ & $4(3.1)$ & $6(1.8)$ & $19(6.4)$ & $4(3.8)$ \\
\hline Aureobasidium & $0(0)$ & $0(0)$ & $2(2.9)$ & $0(0)$ & $0(0)$ & $0(0)$ & $0(0)$ \\
\hline Botrytis & $0(0)$ & $0(0)$ & $2(2.9)$ & $0(0)$ & $0(0)$ & $1(0.3)$ & $0(0)$ \\
\hline Candida albicans & $0(0)$ & $2(0.7)$ & $0(0)$ & $0(0)$ & $0(0)$ & $1(0.3)$ & $0(0)$ \\
\hline Chaetomium & $0(0)$ & $0(0)$ & $3(4.3)$ & $0(0)$ & $0(0)$ & $1(0.3)$ & $0(0)$ \\
\hline Cladosporium & $27(57.4)$ & $145(50.7)$ & $16(23.2)$ & $38(29)$ & $141(42.9)$ & $126(42.4)$ & $36(34)$ \\
\hline Curvularia & $0(0)$ & $1(0.3)$ & $0(0)$ & $1(0.8)$ & $0(0)$ & $1(0.3)$ & $0(0)$ \\
\hline Drechslera & $0(0)$ & $2(0.7)$ & $2(2.9)$ & $1(0.8)$ & $0(0)$ & $1(0.3)$ & $0(0)$ \\
\hline Epicoccum & $0(0)$ & $2(0.7)$ & $0(0)$ & $0(0)$ & $4(1.2)$ & $2(0.7)$ & $3(2.8)$ \\
\hline Fusarium & $0(0)$ & $3(1)$ & $0(0)$ & $0(0)$ & $0(0)$ & $1(0.3)$ & $0(0)$ \\
\hline Geotrichum & $0(0)$ & $4(1.4)$ & $0(0)$ & $0(0)$ & $0(0)$ & $2(0.7)$ & $0(0)$ \\
\hline Mucor & $0(0)$ & $1(0.3)$ & $0(0)$ & $0(0)$ & $0(0)$ & $1(0.3)$ & $2(1.9)$ \\
\hline Neurospora & $0(0)$ & $0(0)$ & $0(0)$ & $1(0.8)$ & $1(0.3)$ & $1(0.3)$ & $0(0)$ \\
\hline Other yeasts & $4(8.5)$ & $62(21.7)$ & $6(8.7)$ & $34(26)$ & $31(9.4)$ & $13(4.4)$ & $7(6.6)$ \\
\hline Penicillium & $2(4.3)$ & $11(3.8)$ & $15(21.7)$ & $20(15.3)$ & $80(24.3)$ & $41(13.8)$ & $20(18.9)$ \\
\hline Phoma & $0(0)$ & $1(0.3)$ & $0(0)$ & $0(0)$ & $1(0.3)$ & $1(0.3)$ & $1(0.9)$ \\
\hline Rhizopus & $2(4.3)$ & $3(1)$ & $4(5.8)$ & $7(5.3)$ & $7(2.1)$ & $6(2)$ & $5(4.7)$ \\
\hline Rhodotorula & $0(0)$ & $0(0)$ & $2(2.9)$ & $1(0.8)$ & $3(0.9)$ & $0(0)$ & $0(0)$ \\
\hline Scopulariopsis & $0(0)$ & $2(0.7)$ & $1(1.4)$ & $0(0)$ & $0(0)$ & $0(0)$ & $0(0)$ \\
\hline Sterile mycelia & $2(4.3)$ & $11(3.8)$ & $6(8.7)$ & $9(6.9)$ & $11(3.3)$ & $10(3.4)$ & $7(6.6)$ \\
\hline Syncephalestrum & $0(0)$ & $0(0)$ & $0(0)$ & $0(0)$ & $0(0)$ & $1(0.3)$ & $0(0)$ \\
\hline Trichoderma & $0(0)$ & $1(0.3)$ & $0(0)$ & $2(1.5)$ & $1(0.3)$ & $0(0)$ & $1(0.9)$ \\
\hline Trichosporon & $0(0)$ & $3(1)$ & $0(0)$ & $0(0)$ & $2(0.6)$ & $0(0)$ & $3(2.8)$ \\
\hline Unknown & $1(2.1)$ & $5(1.7)$ & $4(5.8)$ & $2(1.5)$ & $2(0.6)$ & $2(0.7)$ & $2(1.9)$ \\
\hline Total & $47(100)$ & $286(100)$ & $69(100)$ & $131(100)$ & $329(100)$ & $297(100)$ & $106(100)$ \\
\hline
\end{tabular}


Library of faculty of health (library number 5) showed the most fungal Contamination and of faculty of management and medical information (library number 1), the least (Table 2).

The contamination was revealed in books of reference department, books of circulation department, air of libraries, and book shelves of both reference and circulation departments at the level of $30.7 \%, 26.3 \%, 4.1 \%$, and $38.9 \%$, respectively. Penicillium sp., Cladosporium sp., Alternaria sp., and Aspergillus sp. were the most common fungal species found, and Aureobasidium sp., Syncephalestrum sp., Botrytis sp., and Neurospora sp., were the least species detected in our study. We were not able to identify 18 colonies and reported them as unknown species. In this survey Chi-square statistical test was used to identify significance of fungus redundancy and also the relationship between various cleansing methods and number of fungal agents.

\section{Discussion}

Different species of fungi demonstrated different nutritional patterns; some fed from buckram bindings, and some from leather. One species appeared light tolerant and attacked the spine of the books. Nevertheless other species would only grow on the paper as dark spots (14). Papers had made of plants. Aspergillus and Tricoderma spp. found in libraries of seven faculties in present study have the ability to destroy cell walls of the plants (15). The distribution pattern of fungi species varies; some species are more common in libraries regardless of geographical situation. Compared to our study, previous studies by Ebrahimi et al. (16) show that some fungi species can be observed in all mentioned libraries.

Shamsian et al. (7) studied the fungal contaminations in Historical Manuscripts at Astan Quds Museum Library, Mashhad, Iran. They showed the most fungal Genera were Aspergillus, Penicillium , Mucor spp.. Aspergillus and Penicillium spp. could damage paper. Our study was in line with Shamsian et al. study results. Vittal and Glory (9) found that Aspergillus and Cladosporium spp. were the most common fungi found in printed materials at library building of Madras University in India. Also existence of considerable amounts of Nigrospora, Curvularia, Drechslera, and Alternaria spp. was reported. Also we found this species (Nigrospora, Curvularia, Drechslera, and Alternaria spp.) and Aspergillus and Cladosporium spp. were the most common fungi found in printed materials.

Chadeganipour et al. (17) found that the most abundant airborne fungi identified in Isfahan were Cladosporium sp., Penicillium sp., Aspergillus sp., and Alternaria sp.. These species were found also in our studies. Zotti et al. (8) studied fungal bio-deterioration of historic paper and artistic works and revealed some fungal genera which colonized and damaged them. The colonies they isolated in frequency order were Penicillium, A. flavus , Cladosporium, and Auerobasidium spp. Auerobasidium also was found in reference work department libraries; in our study, it showed almost the least number of colonies; the finding that was similar to what was in Zotti et al. study.

Rojas et al. (18) in a study on fungi causing bio-deterioration of industrial paper in Bogota archive center showed similar results to our study. They found genera of Cladosporium, Chaetomium, Penicillium sacculum, Aspergillus, Penicillium and Alternaria. Species like Chaetomium are soft-rot fungi that grow in woods existing in wet environments (19). Wooden shelves can absorb humidity providing suitable environment for fungal growth. Sunil and Kumar (20) suggested that library racks should be made of steel and suitably painted to avoid rusting.

In chapter six, issue 13 and 14 statute book of Isfahan University there are rules about preserving and maintenance of resource, equipment, and space of a library. These results say paper materials should be kept in metal racks with enamel or stainless covering. In case of using wooden racks, their wood should be compact and tenacious and be covered with high quality acrylic stain (21). Isolation of Cladosporium, Penicillium, Aspergillus, and Alternaria spp. as the most common isolated fungi in Isfahan university of medical sciences libraries, was in agreement with the fungi reported by Vittal et al. (9) in libraries and archives. They also found Chaetomium and Rhizopus spp. which are cellulose destructive fungi in books of library in Madras. Trichoderma sp. is an enzyme producer fungus with several applications in industry (22). The most common ingredients used for repairing old and damaged books such as glues with animal and vegetable sources and inks and wax seals are good nutritional resources for fungal growth (7).

In our study, sampling was performed in three different times during a day; in the morning after cleansing (the hours with the least users in library), at noon (with the most users) and in the evening at the end of working session. Fungal frequency was different each time of sampling and the difference was significant (P value $<0.001$ ). There wasn't any significant relation between cleansing of the library and fungal frequency in morning, noon, and evening ( $P$ value $>0.05)$. Since the fungi was more frequent at morning (after the cleansing), possibly there were other disturbing factors such as temperature, humidity, etc. that have affected on our results. So, it is necessary to study the relationship between these two variants more thoroughly and comprehensively after unifying effective factors and eliminating conditions that disturb

Silva et al. (23) showed that paper and wood damaging fungi will be inactivated by gamma-ray radiation. The research was performed in a Brazilian public library on common species of fungi invading books and documents such as Acremonium, Aspergillus, Cladosporium, Fusarium, Penicillium, and Trichosporon spp. which were inactivated by gamma-ray radiation. For prevention of damage and 
preserving library collections, environmental conditions should be adjusted in a way that fungal growth diminishes. The optimum temperature for this purpose should be between 18 to $22^{\circ} \mathrm{C}$ and humidity should be adjusted below 55\% (7).

We suggest training of librarians as one of the most important steps in librariesto preserve library materials because having no knowledge about threatening factors and the way to fight with them are the main reasons of most frequent damages to library resources. Using new methods and technologies of preserving and maintenance of materials should be a priority in library managers' planning. There are different ways to disinfect and inactivate fungi such as chemicals or radiation procedures (24).

\section{Acknowledgements}

The authors of this article are greatly thankful to Department of Medical Mycology and all of librarians of Isfahan medical university. Also special thanks to Dr. Parvin Dehghan for her cooperation.

\section{Financial Disclosure}

None declared.

\section{Funding Support}

This research was financially supported by research chancellor of medicine school, Isfahan University of medical sciences.

\section{Authors' Contribution}

None declared.

\section{References}

1. Bankole OM. A review of biological deterioration of library materials and possible control strategies in the tropics. Lib Rev. 2010;59(6):414-29.

2. Simon-Nobbe B, Denk U, Poll V, Rid R, Breitenbach M. The spectrum of fungal allergy. Int Arch Allergy Immunol. 2008;145(1):5886.

3. Falih AM. Production Of Extracellular Enzymes By Some Soil Yeasts. Qatar Univ.1997;17(1):97-102.

4. Ohkuma M, Maeda Y, Johjima T, Kudo T. Lignin degradation and roles of white rot fungi: Study on an efficient symbiotic system in fungus-growing termites and its application to bioremediation. Riken Review. 2001; p. 39-42

5. Dennis C. Breakdown of cellulose by yeast species. J Gen Microbiol. 1972;71(2):409.

6. Stevens B, Payne J. Cellulase and xylanase production by yeasts of the genus Trichosporon. J Gen Microbiol.1977;100(2):381-93.

7. Shamsian A, Fata A, Mohajeri M, Ghazvini K. Fungal Contaminations in Historical Manuscripts at Astan Quds Museum Library, Mashhad, Iran. Int J Agr Biol. 2006;8.

8. Zotti M, Ferroni A, Calvini P. Microfungal biodeterioration of historic paper: Preliminary FTIR and microbiological analyses. Int Biodeterioration Biodegrad. 2008;62(2):186-94.

9. Vittal BPR, Glory AL. Airborne Fungus Spores of a Library in India. Grana. 1985;24(2):129-32.

10. Guiamet P, Borrego S, Lavin P, Perdomo I, de Saravia SG. Biofouling and biodeterioration in materials stored at the Historical Archive of the Museum of La Plata, Argentine and at the National Archive of the Republic of Cuba. Colloids Surf B Biointerfaces. 2011;85(2):229-34

11. Shadzi S, Zahraee MH, ChadeganiPour M. Incidence of airborne fungi in Isfahan, Iran. Mycoses. 1993;36(1-2):69-73.

12. Rippon JW.Medical mycology, Philadelphia: WB Saunders Co.1988.

13. Larone DH. Medically important fungi: a guide to identification. 2002.

14. Chamberlain WR. A new approach to treating fungus in small libraries. Abbey Newsletter.1991;15(7):109-11.

15. Juwaied AA, Al-amiery AAH, Abdumuniem Z, Anaam U. Optimization of cellulase production by Aspergillus niger and Tricoderma viride using sugar cane waste. J Yeast Fung Res. 2011;2(2):19-23.

16. Ebrahimi A, Karimi S, Lotfalian S, Majidi F. Allergenic fungi in deteriorating historic objects of Shahrekord Museum, in Iran. JundishapurJ Microbiol. 2012;4(4):261-5.

17. Chadeganipour M, Shadzi S, Nilipour S, Ahmadi G. Airborne fungi in Isfahan and evaluation of allergenic responses of their extracts in animal model. Jundishapur J Microbiol. 2011;3(4):155-60.

18. Rojas JA, Cruz C, Mikán JF, Villalba LS, Cepero de García MC, Restrepo S. Isoenzyme characterization of proteases and amylases and partial purification of proteases from filamentous fungi causing biodeterioration of industrial paper. Int Biodeterioration Biodegrad. 2009;63(2):169-75.

19. Deacon J. Wood decay and wood-rotting fungi. 2005

20. Sunil A, Kumar KP. Preservation of Library Materials: Problems and Perspective. J Lib Inform Technol. 2009;29(4):37-40.

21. Regulation on the protection and preservation of resources, equipment and space library of Isfahan University . www.library. ui.ac.ir.

22. Ahmed S, Bashir A, Saleem H, Saadia M, Jamil A. Production and purification of cellulose-degrading enzymes from a filamentous fungus Trichoderma harzianum. PakJ Bot. 2009;41(3):1411-9.

23. da Silva M, Moraes AML, Nishikawa MM, Gatti MJA, Vallim de Alencar MA, Brandão LE, et al. Inactivation of fungi from deteriorated paper materials by radiation. Int Biodeterioration Biodegrad. 2006;57(3):163-7.

24. Ghahri M. Ghahri M. A review of destructive fungal agents of paper, pathology and prevention. In: Research Ra 2006; p. 27-42 